$p$-ISSN 1693-9484, $e$-ISSN : 2621-8313

Majalah Ilmiah Bahari Jogja (MIBJ)

Vol. 17 No. 2, Juli $2019 \quad$ (51-60)

DOI : 10.33489/mibj.v17i2.209

(C) 2019 Akademi Maritim Yogyakarta

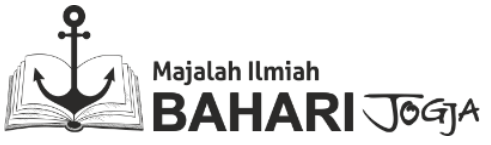

\title{
Pengaruh Kualitas Fungsional Dan Kualitas Teknikal Terhadap Kepuasaan Mahasiswa Peserta Pelatihan Kepabeanan Tahun 2018
}

\author{
Vivid Dekanawati ${ }^{*}$, Supartini $^{1}$ \\ ${ }^{1}$ Ketalaksanaan Pelayaran Niaga, Akademi Maritim Yogyakarta, Jl. Magelang KM 4.4, \\ Yogyakarta 55284, Indonesia \\ * Corresponding Author. Email: vividdek@gmail.com. Hp: +6281910889982
}

\begin{abstract}
Abstrak
Penelitian ini bertujuan untuk mengetahui: kualitas fungsional yaitu kepedulian, keramah tamahan dan profesionalisme. Kualitas teknikal dengan indikator yaitu ketetapan waktu, kecepatan pelayanan dan kerapian hasil, sehingga peserta pelatihan dapat menilai pelayanan setelah responden yang bersangkutan melakukan pelatihan kepabeanan di Akademi Maritim Yogyakarta (AMY). Populasi dalam penelitian ini adalah seluruh taruna AMY semester V sebagai peserta pelatihan kepabeanan. Sampel yang diambil dalam penelitian ini adalah mahasiswa atau yang disebut taruna yang telah mengikuti pelatihan kepabeanan tahun 2018 sejumlah 125 peserta. Teknik pengambilan sampel secara sensus. Dalam penelitian ini penulis menggunakan metode analisis regresi linier berganda yaitu analisis tentang pengaruh variabel bebas $(\mathrm{X})$ yang lebih dari satu terhadap variabel terikat (Y). Analisis data pada penelitian ini menggunakan bantuan SPPS versi 17.0 dan untuk menguji hipotesis menggunakan regresi linear berganda. Hasil dari penelitian ini berdasarkan hasil uji $\mathrm{F}$ menunjukkan variabel-variabel kualitas fungsional dan kualitas teknikal berpengaruh secara simultan terhadap kepuasaan peserta. Hasil uji t untuk variabel kualitas teknikal tidak ada pengaruh yang signifikan terhadap kepuasaan peserta. Hasil uji koefisien determinasi bersamasama dipengaruhi oleh variabel lain selain kualitas fungsional dan kualitas teknikal. Berdasarkan hasil analisis metode stepwise Kualitas fungsional berpengaruh paling dominan terhadap kepuasan peserta.
\end{abstract}

\section{Kata Kunci: Kualitas Fungsional, Kualitas Teknikal, Kepuasan Mahasiswa}

\begin{abstract}
This study aims to find out: functional quality, namely caring, hospitality and professionalism. Technical quality with indicators, namely the determination of time, service speed and neatness of results, so that trainees can assess service after the respondent in question conducts customs training at the Yogyakarta Maritime Academy (AMY). The population in this study were all AMY semester V cadets as customs training participants. The samples taken in this study were students or so-called cadets who had attended 2018 customs training in a number of 125 participants. Census sampling technique. In this study the author uses a multiple linear regression analysis method, which is an analysis of the influence of more than one independent variable $(X)$ on the dependent variable $(Y)$. Data analysis in this study used the help of SPPS version 17.0 and to test hypotheses using multiple linear regression. The results of this study based on the results of the
\end{abstract}


$F$ test show the variables of functional quality and technical quality have a simultaneous influence on the satisfaction of participants. The results of the test for technical quality variables have no significant effect on participant satisfaction. The test results of the coefficient of determination are jointly influenced by other variables besides functional quality and technical quality. Based on the results of the analysis of the stepwise method Functional quality has the most dominant effect on participant satisfaction

\section{Keywords: Functional quality, technical quality and satisfaction students}

\section{PENDAHULUAN}

Menurut UU RI nomer 17 tahun 2006, menyebutkan bahwa pengurusan pemberitahuan pabean di kantor Pabean dapat dilakukan sendiri oleh Importir maupun Eksportir. Apabila tidak dapat dilakukan sendiri, maka importir dan eksportir dapat menguasakannya kepada Pengusaha Pengurusan Jasa Kepabeanan (PPJK). Pelatihan Kepabeanan sangat penting dibekali kepada Taruna-Taruni Akademi Maritim Yogyakarta (AMY) semester 5 sebagai bagian menyediakan tenaga ahli dibidang Kepabeanan. Pelatihan Kepabeanan diselenggarakan setiap tahun oleh AMY, dan setiap akhir pelatihan ada kuesioner sebagai bagian dari evaluasi terhadap pelaksanaan pelatihan tersebut.

Pengertian tentang kualitas pelayanan menurut Tjiptono (2000:52) adalah suatu kondisi dinamis yang berhubungan dengan produk, manusia, proses dan lingkungan yang memenuhi harapan. Sedangkan menurut Tjiptono (2004:59) kualitas pelayanan terdiri dari tiga dimensi atau komponen utama yang terdiri dari : 1)Technical Quality yaitu komponen yang berkaitan dengan kualitas output (keluaran) jasa yang diterima konsumen. 2) Functional Quality yaitu komponen yang berkaitan dengan kualitas cara penyampaian suatu jasa. 3)Corporate Image yaitu profil, reputasi, citra umum dan daya tarik khusus suatu perusaan.

Gronross (dalam Tjiptono 2011), pada dasarnya kualitas suatu jasa yang dipersepsikan pelanggan terdiri atas dua dimensi utama. Dimensi Pertama, Technical Quality (outcome dimension) berkaitan dengan kualitas output jasa yang dipersepsikan pelanggan. Kualitas teknikal adalah landasan keberhasilan bagi penyedia jasa dalam waktu lama, sehingga pelanggan dapat menilai pelayanan dalam jangka panjang. Komponen ini dapat dijabarkan lagi menjadi tiga jenis nyakni : a). Search quality (dapat dievaluasi sebelum dibeli, misalnya harga). b). Experience quality (hanya bisa dievaluasi setelah dikonsumsi, contohnya ketepatan waktu, kecepatan layanan, dan kerapian hasil). C). Credence quality (sukar dievaluasi pelanggan sekalipun telah mengkonsumsi jasa, contohnya kualitas operasi bedah jantung).

Dimensi Kedua, Functional Quality (process-related dimension) berkaitan dengan kualitas cara penyampaian jasa atau menyangkut proses transfer kualitas teknis, output atau hasil akhir jasa dari penyedia jasa kepada pelanggan. Dimana kualitas fungsional meliputi dimensi kontak pelanggan, sikap, perilaku pelanggan, hubungan internal, penampilan dan rasa melayani. Karena pada umumnya lebih memiliki ciri kualitas berdasarkan pengalaman dan kepercayaan, maka pelanggan akan merasakan risiko yang lebih tinggi dalam membeli jasa. Contohnya meliputi 
bagaimana petugas rumah sakit berpenampilan dan berprilaku dalam pelayanan pasien yang rawat inap, serta bagaimana para karyawan melakukan tugas mereka serta apa saja yang mereka ucapkan.

Sharma dan petterson dan Ravald dan Gronroos (dalam Indriastanti 2008), kualitas teknikal dengan indikator yaitu kepetapan waktu, kecepatan pelayanan dan kerapian hasil. Sedangkan indikator untuk mengukur kualitas fungsional adalah kepedulian, keramah tamahan dan profesionalisme, secara grafis dimensionalisasi dapat digambarkan.

Menurut Kolter dan Keller (2009:177) kepuasan adalah perasaan senang atau kecewa seseorang yang muncul setelah membandingkan kinerja (hasil) produk yang dipikirkan terhadap kinerja (hasil) yang di harapkan, jika kinerja berada di bawah harapan maka pelanggan tidak puas namun jika memenuhi harapan pelanggan puas dan jika kinerja melebihi harapan maka akan merasa sangat puas.

Menurut Tjiptono (2006:340) mengatakan bahwa kepuasan pelanggan dapat juga di definisikan sebagai keseluruhan sikap yang di tunjukkan pelanggan atas barang atau jasa setelah mereka memperoleh dan menggunakannya.

Kepuasan pelanggan dapat didefinisikan sebagai respon efektif terhadap pengalaman melakukan konsumsi yang spesifik atau suatu evaluasi kesesuaian atau ketidaksesuaian yang dirasakan antara harapan sebelumnya dan kinerja aktual produk setelah pemakaian(Oliver pada Birgelan et al., 2000).

Penelitian Chandra Kuswoyo dan Rully Arlan Tjahyadi (2017), menunjukkan Kualitas fungsional (functional quality) berpengaruh positif pada kepuasan pelanggan, sedangkan Kualitas teknis (tehnical quality) tidak berpengaruh pada kepuasan pelanggan.

Penelitian Sarah Cesar Riani (2018), menunjukkan hasil Kualitas Fungsional dan Kualitas Teknis tidak memiliki efek positif yang signifikan terhadap Kepuasan Pelanggan.

Berdasarkan penjelasaan tersebut, maka keranga pemikiran dalam penelitian ini digambarkan sebagai berikut :

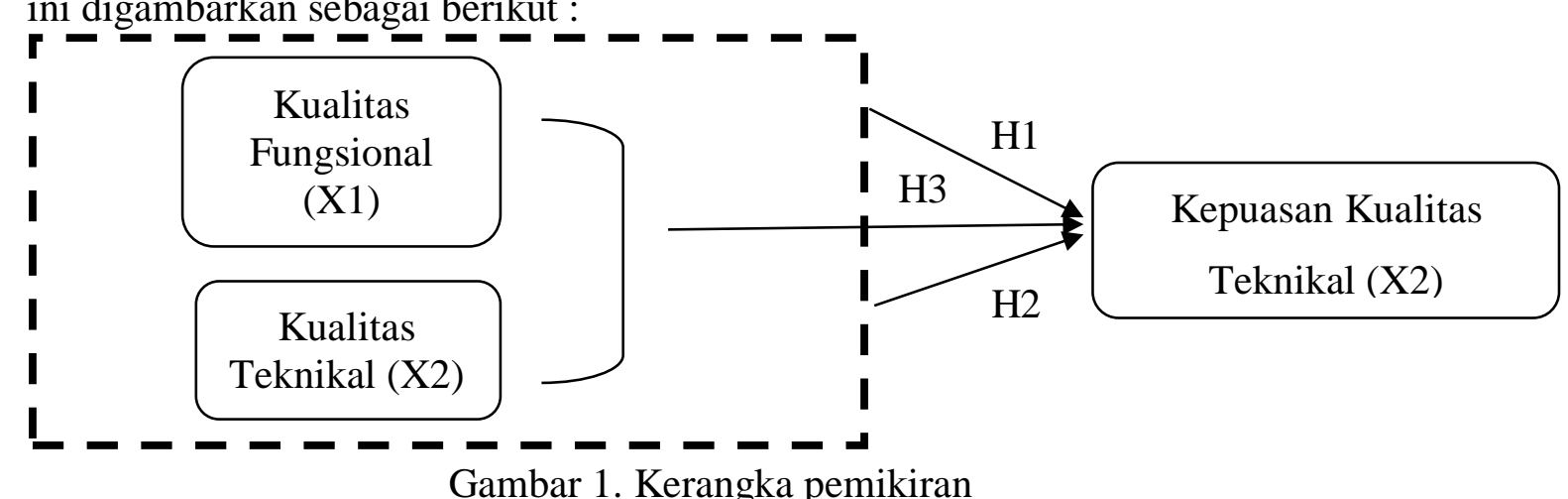

Berdasarkan uraian diatas, maka tujuan dari penelitian ini untuk menguji pengaruh kualitas fungsional dan kualitas teknikal terhadap kepuasaan taruna sebagai peserta pelatihan secara serempak maupun secara parsial dan untuk menguji mana yang paling berpengaruh terhadap kepuasan. 


\section{METODE}

Penelitian ini bersifat asosiatif/hubungan. Penelitian asosiatif merupakan penelitian yang bertujuan untuk mengetahui hubungan atau pengaruh antara dua variabel atau lebih. Variabel dalam penelitian ini ada 2 yaitu Variabel independen yaitu variabel kualitas fungsional dan variabel kualitas teknikal. Variabel dependen yaitu Kepuasan peserta.

Populasi dalam penelitian ini adalah seluruh taruna AMY semester V sebagai peserta pelatihan kepabeanan. Sampel yang diambil dalam penelitian ini adalah taruna yang telah mengikuti pelatihan kepabeanan sebanyak 125 peserta. Teknik pengambilan sampel secara sensus.

Jenis data dalam penelitian ini adalah data primer, semua taruna yang ikut pelatihan di AMY. Karena jenis data yang di gunakan adalah primer, maka metode yang digunakan adalah pengumpulan data secara langsung. Dalam penelitian ini data dikumpulkan dengan menyebarkan kuesioner yang berisi sejumlah pertanyaan kepada para responden. Teknik pengumpulannya yaitu peneliti memberikan kuesioner kualitas fungsional, kualitas teknikal dan kepuasan peserta setelah responden yang bersangkutan melakukan pelatihan kepabeanan.

Dalam penelitian ini penulis menggunakan metode analisis regresi linier berganda yaitu analisis tentang pengaruh variabel bebas (X) yang lebih dari satu terhadap variabel terikat (Y). Analisis data pada penelitian ini menggunakan bantuan SPPS versi 17.0.

Uji kelayakan instrument dengan menggunakan uji validitas dan uji reliabilitas. Analisis ini digunakan untuk menguji valid tidaknya setiap pernyataan yang ada dalam kuesioner.

Uji F statistika yaitu Pengujian secara serentak (simultan) menggunakan uji F statistik untuk mengetahui apakah terdapat pengaruh atau tidak antara variabel bebas secara bersama-sama terhadap variabel terikatnya. Jika F hitung lebih besar dari $\mathrm{F}$ tabel, maka terdapat pengaruh antara variabel bebas secara bersama-sama terhadap variabel terikat.

Uji t statistik yaitu Uji ini dilakukan untuk mengetahui apakah ada pengaruh antara variabel bebas dengan variabel terikat secara parsial. Jika t hitung lebih besar dari t-tabel, maka variabel bebasnya mempunyai pengaruh secara parsial terhadap variabel terikat, demikian pula sebaliknya.

Koefisien determinasi Untuk mengukur poporsi/presentasi sumbangan dari seluruh variabel bebas $(\mathrm{X})$ yang terdapat dalam model regresi terhadap variabel terikat (Y) menurut Djawanto(1994:168).

Metode stepwise digunakan bila analisis regresi yang digunakan secara bertahap. Tujuannya adalah untuk mencari variabel bebas atau variabel prediktor mana yang pengaruhnya paling besar (Hartono:97).

\section{HASIL DAN PEMBAHASAN}

1. Karakteristik Responden

Berdasarkan olahan data karakteristik responden berdasarkan jenis kelamin dapat diketahui bahwa dari 125 responden yang diambil sebagai sampel pada penelitian ini dapat di ketahui bahwa responden terbanyak dalam 
penelitian ini mayoritas laki-laki yaitu jumlah 111 orang $(88.8 \%)$ sedangkan responden perempuan berjumlah 14 orang (11.2\%). Hal ini menunjukkan bahwa mayoritas peserta pelatihan diklat adalah laki-laki.

Sedangkan untuk karakteristik responden berdasarkan usia, dari 125 responden. Di ketahui bahwa responden terbanyak berusia antara 20-21 tahun sebanyak 86 orang $(68,8 \%)$, usia $<20$ tahun berjumlah 22 orang $(17,6 \%)$ dan usia $>21$ tahun berjumlah 17 orang $(13,6 \%)$.

2. Uji Instrumen

a) Uji Validitas

Tabel 1 Hasil Uji Validitas Variabel Kualitas Fungsional (X1)

\begin{tabular}{|c|c|c|c|}
\hline Butir & $\begin{array}{c}\text { Nilai r } \\
\text { (correlation) }\end{array}$ & $\begin{array}{c}\text { Nilai } \\
\text { Sig }\end{array}$ & Ket \\
\hline X1.1 & 0,605 & 0,000 & Valid \\
\hline X1.2 & 0,447 & 0,000 & Valid \\
\hline X1.3 & 0,447 & 0,000 & Valid \\
\hline X1.4 & 0,570 & 0,000 & Valid \\
\hline X1.5 & 0,461 & 0,000 & Valid \\
\hline X1.6 & 0,489 & 0,000 & Valid \\
\hline X1.7 & 0,371 & 0,000 & Valid \\
\hline X1.8 & 0,625 & 0,000 & Valid \\
\hline
\end{tabular}

Sumber : Data primer diolah, 2019

Tabel 1 diatas menunjukan bahwa semua butir pernyataan dari variabel kualitas fungsional dinyatakan valid karena semua butir mempunyai korelasi dengan taraf signifikansi $\langle 0,05$ dan nilai $r$ hitung $>$ 0,174 ( $\mathrm{r}$ tabel).

Tabel 2 Hasil Uji Validitas Variabel Kualitas Teknikal (X2)

\begin{tabular}{|c|c|c|c|}
\hline Butir & $\begin{array}{c}\text { Nilai r } \\
\text { (correlation) }\end{array}$ & $\begin{array}{c}\text { Nilai } \\
\text { Sig }\end{array}$ & Ket \\
\hline X2.1 & 0,668 & 0,000 & Valid \\
\hline X2.2 & 0,401 & 0,000 & Valid \\
\hline X2.3 & 0,584 & 0,000 & Valid \\
\hline X2.4 & 0,347 & 0,000 & Valid \\
\hline X2.5 & 0,503 & 0,000 & Valid \\
\hline X2.6 & 0,664 & 0,000 & Valid \\
\hline X2.7 & 0,402 & 0,000 & Valid \\
\hline X2.8 & 0,668 & 0,000 & Valid \\
\hline
\end{tabular}

Sumber : Data primer diolah, 2019 
Tabel 2 diatas menunjukan bahwa semua butir pernyataan dari variabel kualitas teknikal dinyatakan valid karena semua butir mempunyai korelasi dengan taraf signifikansi $<0,05$ dan nilai $r$ hitung $>0,174$ ( $\mathrm{r}$ tabel).

Tabel 3 Hasil Uji Validitas Variabel Kepuasaan Peserta (Y)

\begin{tabular}{|c|c|c|c|}
\hline Butir & $\begin{array}{c}\text { Nilai r } \\
\text { (correlation) }\end{array}$ & $\begin{array}{c}\text { Nilai } \\
\text { Sig }\end{array}$ & Ket \\
\hline Y.1 & 0,224 & 0,012 & Valid \\
\hline Y.2 & 0,825 & 0,000 & Valid \\
\hline Y.3 & 0,567 & 0,000 & Valid \\
\hline Y.4 & 0,757 & 0,000 & Valid \\
\hline Y.5 & 0,399 & 0,000 & Valid \\
\hline Y.6 & 0,825 & 0,000 & Valid \\
\hline Y.7 & 0,488 & 0,000 & Valid \\
\hline Y.8 & 0,827 & 0,000 & Valid \\
\hline
\end{tabular}

Sumber : Data primer diolah, 2019

Tabel 3 diatas menunjukan bahwa semua butir pernyataan dari variabel kepuasaan peserta dinyatakan valid karena semua butir mempunyai korelasi dengan taraf signifikansi $<0,05$ dan nilai $r$ hitung $>0,174$ ( $\mathrm{r}$ tabel).

b) Uji Reliabel

Tabel 4 Hasil Uji Reliabel

\begin{tabular}{|l|c|c|}
\hline \multicolumn{1}{|c|}{ Variabel } & Alpha Cronbach & ket \\
\hline $\begin{array}{l}\text { Kualitas Fungsional } \\
\text { (X1) }\end{array}$ & 0,705 & Reliabel \\
\hline Kualitas Teknikal (X2) & 0,718 & Reliabel \\
\hline Kepuasaan Peserta (Y) & 0,750 & Reliabel \\
\hline
\end{tabular}

Sumber : Data primer diolah, 2019

Dari diatas bahwa pada ketiga variabel yaitu kualitas fungsional (X1), kualitas teknikal (X2), kepuasaan peserta (Y) Alpha Cronbach menunjukkan nilai lebih dari 0,7 sehingga dikatakan bahwa instrumen yang digunakan di dalam penelitian memiliki reliabilitas yang baik.

Dari hasil uji validitas dan reliabilitas yang telah dilakukan, maka dapat disimpulkan bahwa kuesioner sudah layak untuk digunakan sebagai instrumen penelitian. 
c) Analisis Regresi Linier Berganda

Tabel 5 Hasil pengujian regresi linier berganda

Coefficients $^{a}$

\begin{tabular}{|c|c|c|c|c|c|c|c|c|}
\hline \multirow{2}{*}{\multicolumn{2}{|c|}{ Model }} & \multicolumn{2}{|c|}{$\begin{array}{l}\text { Unstandardized } \\
\text { Coefficients }\end{array}$} & \multirow{2}{*}{$\begin{array}{c}\text { Standardized } \\
\text { Coefficients } \\
\text { Beta }\end{array}$} & \multirow[b]{2}{*}{$\mathrm{t}$} & \multirow[b]{2}{*}{ Sig. } & \multicolumn{2}{|c|}{$\begin{array}{l}95,0 \% \text { Confidence } \\
\text { Interval for B }\end{array}$} \\
\hline & & B & Std. Error & & & & $\begin{array}{l}\text { Lower } \\
\text { Bound }\end{array}$ & $\begin{array}{l}\text { Upper } \\
\text { Bound }\end{array}$ \\
\hline \multirow[t]{3}{*}{1} & (Constant) & 8.801 & 3.070 & & 2.867 & .005 & 2.723 & 14.878 \\
\hline & Kualitas Fungsional & .376 & .170 & .298 & 2.207 & .029 & .039 & .713 \\
\hline & Kualitas Teknikal & .331 & .162 & .277 & 2.046 & .043 & .011 & .650 \\
\hline
\end{tabular}

a. Dependent Variable: Kepuasaan Peserta

Berdasarkan tabel 5 coefficients diatas maka dapat diperoleh persamaan regresi yaitu :

$$
\mathrm{Y}=8,801+0,376 \mathrm{X} 1+0,331 \mathrm{X} 2
$$

Dari persamaan regresi linier berganda dalam tabel di atas dapat di ketahui bahwa : 1) Kontanta a = 8,801 Artinya jika skor variabel kualitas fungsional, kualitas teknikal konstan atau 0, maka skor kepuasaan peserta 8,801. 2). Nilai koefisien regresi kualitas fungsional (b1) yang bertanda positif $(0,376)$ menunjukkan adanya pengaruh yang positif antara kualitas fungsional dengan kepuasan peserta. Artinya jika kualitas fungsional yang diberikan bagus dan berkesan untuk peserta maka kepuasan peserta meningkat. 3) Nilai koefisien regresi kualitas teknikal (b2) yang bertanda positif $(0,331)$ menunjukkan adanya pengaruh yang positif antara kualitas teknikal dengan kepuasaan peserta.

Dari hasil koefisien regeresi kedua variabel yang bernilai positif, berarti variabel independen tersebut mempunyai pengaruh positif terhadap variabel dependen.

d) Uji F

Tabel 6 Hasil nilai uji F

ANOVA $^{\mathrm{b}}$

\begin{tabular}{|ll|r|r|r|r|r|}
\hline Model & & Sum of Squares & df & Mean Square & F & Sig. \\
\hline 1 & Regression & 546.217 & 2 & 273.109 & 26.448 & $.000^{\mathrm{a}}$ \\
& Residual & 1259.783 & 122 & 10.326 & & \\
& Total & 1806.000 & 124 & & & \\
\hline
\end{tabular}

a. Predictors: (Constant), Kualitas Teknikal, Kualitas Fungsional

b. Dependent Variable: Kepuasaan Peserta

Dari hasil tabel 6 pengolahan data diatas diketahui bahwa nilai Fhitung adalah 26,448 dengan nilai signifikan sebesar 0,000, dan nilai F-tabel adalah 3,090 dengan demikian dapat di simpulkan bahwa F-hitung > F-tabel dengan tingkat signifikan 0,000 $<0,05(\mathrm{p}<0,05)$, maka Ho ditolak dan Ha diterima berarti variabel-variabel kualitas fungsional dan kualitas teknikal berpengaruh secara simultan terhadap kepuasaan peserta. 
e) Uji T

Tabel 7 Hasil nilai uji t

\begin{tabular}{|l|l|l|c|c|}
\hline \multicolumn{1}{|c|}{ Variabel } & T hitung & T tabel & Sig & Ket \\
\hline Kualitas fungsional & 2,207 & 1,660 & 0,029 & Signifikan \\
\hline Kualitas teknikal & 2,046 & 1,660 & 0,043 & Signifikan \\
\hline
\end{tabular}

Dari hasil olah data di atas diketahui t-hitung masing-masing variabel adalah:

Variabel kualitas fungsional t-hitung lebih besar dari t-tabel $(2,207>1,660)$ dengan porbalitas $(0,029)$ lebih kecil dari taraf signifikan 0,05 dengan demikinan Ho di tolak dan Ha diterima, artinya variabel kualitas fungsional mempunyai pengaruh yang signifikan terhadap kepuasaan peserta dan Variabel kualitas teknikal t-hitung lebih besar dari ttabel $(2,046>1,660)$ dengan porbalitas $(0,043)$ lebih besar dari taraf signifikan 0,05 dengan demikinan Ho di terima dan Ha ditolak, artinya variabel kualitas teknikal tidak ada pengaruh yang signifikan terhadap kepuasaan peserta.

f) Koefisien determinasi

Tabel 8 Hasil analisis uji koefisien determinasi

\begin{tabular}{l|r|r|r|c|}
\hline Model & $\mathrm{R}$ & $\mathrm{R}$ Square & $\begin{array}{c}\text { Adjusted R } \\
\text { Square }\end{array}$ & $\begin{array}{c}\text { Std. Error of the } \\
\text { Estimate }\end{array}$ \\
\hline 1 & $.550^{\mathrm{a}}$ & .302 & .291 & 3.21342 \\
\hline
\end{tabular}
a. Predictors: (Constant), Kualitas Teknikal, Kualitas Fungsional
b. Dependent Variable: Kepuasaan Peserta

Dari perhitungan diatas diperoleh nilai besarnya koefisien determinasi adalah 0,291 hal ini menunjukkan bahwa pengaruh variabel independen (kualitas fungsional dan kualitas teknikal) terhadap variabel dependen (kepuasaan peserta) adalah 29,1\%. Sedangkan 70,9\% dipengaruhi oleh variabel lain selain kualitas fungsional dan kualitas teknikal.

g) Metode stepwise

Tabel 9 Hasil analisis metode stepwise

\begin{tabular}{|c|c|c|c|c|c|c|c|}
\hline \multirow[b]{2}{*}{ Model } & \multicolumn{2}{|c|}{$\begin{array}{l}\text { Unstandardized } \\
\text { Coefficients }\end{array}$} & \multirow{2}{*}{$\begin{array}{c}\text { Standardized } \\
\text { Coefficients } \\
\text { Beta }\end{array}$} & \multirow[b]{2}{*}{$\mathrm{t}$} & \multirow[b]{2}{*}{ Sig. } & \multicolumn{2}{|c|}{$\begin{array}{l}95,0 \% \text { Confidence } \\
\text { Interval for B }\end{array}$} \\
\hline & B & Std. Error & & & & $\begin{array}{l}\text { Lower } \\
\text { Bound }\end{array}$ & $\begin{array}{l}\text { Upper } \\
\text { Bound }\end{array}$ \\
\hline 1 (Constant) & 8.801 & 3.070 & & 2.867 & .005 & 2.723 & 14.878 \\
\hline Kualitas Fungsional & .376 & .170 & .298 & 2.207 & .029 & .039 & .713 \\
\hline Kualitas Teknikal & .331 & .162 & .277 & 2.046 & .043 & .011 & .650 \\
\hline
\end{tabular}

a. Dependent Variable: Kepuasaan Peserta 
Di lihat dari tabel 9 diperoleh variabel yang dominan mempengaruhi kepuasan peserta (Y) adalah kualitas fungsional (X1). Ini dilihat dari nilai uji stepwise yang paling dominan mempengaruhi kepuasan peserta $(\mathrm{Y})$ adalah kualitas fungsional (X1). Ini juga dilihat dari nilai t 2,207 dengan tingkat porbabilitas 0,029 .

\section{SIMPULAN}

\section{Kesimpulan}

Berdasarkan analisis data dan pembahasan hasil penelitian, dapat diambil kesimpulan sebagai berikut :

1. Hasil analisis regerensi linier berganda menghasilkan persamaan regeresi $\mathrm{Y}=8,801+0,376 \mathrm{X} 1+0,331 \mathrm{X} 2$

2. Kualitas fungsional dan kualitas teknikal secara simultan berpengaruh terhadap kepuasan peserta. Berdasarkan hasil uji F dengan F-hitung $(26,448)>$ F-tabel $(3,090)$ dan tingkat signifikan $0,000<0,05$.

3. Kualitas fungsional berpengaruh positif signifikan terhadap kepuasan peserta. Berdasarkan hasil uji t dengan t-hitung $(2,207)>\mathrm{t}$-tabel $(1,660)$ dan dengan tingkat signifikan $0,029<0,05$. Artinya kualitas fungsional yang di berikan bagus dan berkesan untuk peserta maka kepuasan peserta meningkat.

4. Kualitas teknikal berpengaruh positif signifikan terhadap kepuasan peserta. Berdasarkan hasil uji $\mathrm{t}$ dengan t-hitung $(2,046)>\mathrm{t}$-tabel $(1,660)$ dan dengan tingkat signifikan $0,043>0,005$. Adanya pengaruh yang positif ini antara kualitas teknikal dengan kepuasaan peserta.

5. Kualitas fungsional berpengaruh paling dominan terhadap kepuasan peserta. Berdasarkan hasil analisis metode stepwise dengan nilai t 2,207 dengan tingkat porbabilitas 0,029 dan berdasarkan hasil analisis uji koefisien determinasi besarnya koefisien determinasi adalah 0,291 hal ini menunjukkan bahwa pengaruh variabel independen (kualitas fungsional dan kualitas teknikal) terhadap variabel dependen (kepuasan peserta) adalah 29,1\%. Sedangkan 70,9\% dipengaruhi oleh variabel lain selain kualitas fungsional dan kualitas teknikal.

\section{Saran}

1. Kedepannya AMY sebagai penyelenggara perlu melakukan perbaikan di alat bantu pelatihan seperti sound system yang tidak ada saat itu dan beberapa kali mengalami mati listrik dari PLN.

2. Perlu interaksi antara Pelatih dengan peserta agar suasana lebih ceria dan tidak tegang.

3. Layanan panitia acara lebih ditingkatkan terkait makanan.

\section{DAFTAR PUSTAKA}

Christopher Lovelock, Jochen Wirtz, Jacky Mussry, 2010. Pemasaran Jasa Manusia, Teknologi, Strategi, Edisi Ketujuh, Erlangga Jakarta.

Craven, David W, 1996. Pemasaran Strategi, Edisi keempat, Penerbit Erlangga, Jakarta. 
David Osborneo, Ted Gaebler, 2007. Mewirausahakan Birokrasi, Mentransformasi Semangat Wirausaha ke dalam Sektor Publik, PT Pustaka Binaman Pressindo, Jakarta.

Dwiyanto, Agus, 2006. Reformasi Birokrasi Publik di Indonesia, Gajah Mada University Press, Yogyakarta.

Fandy Tjiptono, 2011. Pemasaran Jasa, Bayumedia Publising, Jatim.

Ferdinand Augusty, 2011. Metode Peneltian manajemen, Edisi Tiga, Badan Penerbit, Universitas Diponegoro, Semarang.

Fred R. David, 2007. Strategi Management, Manajemen Strategi, Konsep, Penerbit Salemba, Jakarta.

Gazali, 2006. Aplikasi Analisis Multivariate dengan SPSS, Edisi Kedua. BPFE Universitas Diponegoro, Semarang.

Indriastanti, 2008. Analisis Faktor-Faktor Yang Mempengaruhi Kualitas Teknikal Dan Dampaknya Terhadap Komitmen Hubungan Dari Pelanggan, Tesis, Pascasarjana Magister Manajemen Universitas Diponegoro, Semarang.

Kotler, Philip dan Keller, Kevin Lane, 2007. Manajemen Pemasaran, edisi kedua belas, edisi Bahasa Indonosia, PT Indeks Jakarta.

Leon G. Schiffman, Leslie Lazar Kanuk, 2011. Prilaku Konsumen, Edisi Ketujuh, PT. Indeks, Jakarta.

Mahmudi, 2008. Manajemen Kinerja Sektor Publik, Penerbit UPP AMP YKPN, Yogyakarta.

Muh Subhan, 2008. Analisis Faktor-Faktor Yang Berpengaruh Terhadap Reputasi Sutau Perusahaan, Tesis Program Pascasarjana Magister Managemen Universitas Diponegoro, Semarang.

Mudrajad Kuncoro, 2007. Metode Penelitian Kuantitatif, Teori dan Aplikasi, Edisi Kedua.

Payne Adrian, 2010. Services Marketing, Pemasaran Jasa, Andi bekerja sama dengan Pearson Sducation Asia Pte. Ltd.

Philip Kotler, Nancy Lee, Pemasaran di Sektor Publik, 2007. Panduan Praktis untuk Meningkatkan Kinerja Pemerintah, Edisi Bahasa Indonesia, PT Indeks, Jakarta.

Purwanto, Suharyadi, 2007. Statistik untuk Ekonomi dan Keuangan Modern, Buku I, II, Penerbit Salemba Empat, Jakarta.

Sekaran U. 2009. Research Methods For Business, Metode Penelitian Untuk Bisnis, Salemba Empat, Jakarta.

Suliyanto, 2007. Metode Penelitian Bisnis, Bandung Alfabet.

Sugiono, 2008. Metode Penelitian Bisnis, Bandung Alfabet. 